\title{
The relation between maternal work, ambulatory blood pressure, and pregnancy hypertension
}

\author{
J R Higgins, J J Walshe, R M Conroy, M R N Darling
}

J Epidemiol Community Health 2002;56:389-393

See end of article for authors' affiliations

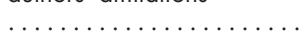

Correspondence to: Professor J R Higgins, Department of Obstetrics and Gynaecology, University College Cork, Erinville Hospital, Western Road, Cork, Ireland; j.higgins@ucc.ie

Accepted for publication 12 September 2001

\begin{abstract}
Study objective: The purpose of the study was to determine the relations between maternal work, ambulatory blood pressure in mid-pregnancy, and subsequent pregnancy outcome.

Design: Data were studied on 933 healthy normotensive primigravidas who had been enrolled into a study on the predictive value of ambulatory blood pressure measurement performed between 18 and 24 weeks gestation. They were classified into three groups depending on whether they were at work (working group, $n=245$ ), not working (not working group, $n=289$ ), or normally employed but chose not to work (ENK group, $n=399$ ), on the day monitoring was performed.

Setting: The Rotunda Hospital (a large maternity hospital), Dublin, Ireland.

Main results: Adjusted for age, body mass index, smoking, drinking, and marital status, women at work had higher mean daytime systolic $(p<0.01)$ and diastolic $(p<0.01)$ and 24 hour systolic pressures $(p=0.03)$ compared with those not working. The rate of subsequent development of pre-eclampsia was significantly higher (odds ratio $4.1,95 \% \mathrm{Cl} 1.1$ to $15.2, \mathrm{p}=0.03$ ) among those at work compared with those not working. The association between pre-eclampsia and maternal work remained significant (odds ratio $5.5,95 \% \mathrm{Cl} 1.1$ to $27.8, \mathrm{p}=0.04$ ) even after allowing for the confounding factors of age, smoking, body mass index, and marital status. When daytime systolic and diastolic blood pressure were added to the regression analysis the risk ratios for pre-eclampsia remained high but did not quite reach statistical significance (odds ratio $4.7,0.90$ to $24.8, p=0.066$ ). Birth weight and placental weight were not predicted by work status or blood pressure.

Conclusions: A significant independent relation was found between maternal work and ambulatory blood pressure levels in mid-pregnancy. In addition, it was found that maternal work was significantly associated with the subsequent development of pre-eclampsia
\end{abstract}

1 n contemporary Western society, more women than ever before continue to work outside the home during pregnancy. ${ }^{1}$ For example, more than half of American resident physicians continue to work up to the day before or the day of delivery. ${ }^{2}$ The effect of maternal employment on pregnancy outcome remains controversial. It has been suggested that maternal work, particularly if continued into the third trimester, is associated with an increased incidence of preterm delivery, a decrease in mean birth weight, and an increased incidence of pre-eclampsia. ${ }^{3-5}$ The mechanism for these associations is unclear. Recently, it has been reported that there is a continuous inverse relation between fetal growth and maternal ambulatory blood pressure, throughout the range seen in normal pregnancy. ${ }^{6}$ However, little is known regarding the effect of work on the absolute level of blood pressure in pregnant women. The advent of ambulatory blood pressure measurement allows multiple blood pressure readings to be taken in a non-clinic setting and, thus, increases the precision and reproducibility of blood pressure measurements. ${ }^{7}$ Using this technique, studies in non-pregnant populations have reported that mean work day pressures can be significantly increased compared with non-work days. ${ }^{89}$ We undertook this study to ascertain if maternal work outside the home, during pregnancy, is indeed associated with significant changes in maternal blood pressure levels and to assess the relation between maternal work, ambulatory blood pressure in mid-pregnancy, and subsequent pregnancy outcome.

\section{METHODS}

The study population consisted of a group of healthy normotensive primigravidas recruited from the antenatal clinics of the Rotunda Hospital, Dublin for 24 hour ambulatory blood pressure measurement between 18 and 24 weeks gestation. Primigravidas were selected because of their known higher risk of pre-eclampsia. All women were white. To ensure a representative sample, recruitment took place in the public, semiprivate, and private antenatal clinics. All women were partaking in a study on the predictive value of ambulatory blood pressure measurement. ${ }^{10}$ Specific exclusion criteria included a history of hypertension, renal disease, cardiac disease and/or diabetes milletus. Women doing night shift work or part-time work were also excluded. All women gave written informed consent.

Basic subject details including maternal age, height, weight, gestation, marital status, alcohol intake, and smoking were recorded. Ambulatory blood pressure monitoring was performed on all subjects using SpaceLabs 90207 monitors (SpaceLabs, Redmond, Washington, USA) that have been specifically validated for use in pregnancy. ${ }^{11}$ The monitors were calibrated at the beginning of the study and then recalibrated every 12 weeks. Recordings were taken half hourly, throughout the 24 hour period. To minimise motion artefact, the women were asked to stand or sit still with their arm resting at their side during each reading. The women were asked to keep an activity diary. For a monitoring event to be deemed successful a minimum number of 18 valid daytime (0900$2100), 10$ valid night time (0000-0700), and 36 readings overall were required. Of 1102 women recruited to the predictive study, 1048 had sufficient ambulatory blood pressure readings to be included in the analysis. Based on their activity diary, it was possible to classify 933 of these depending on whether they were at work (working group, $\mathrm{n}=245$ ), not working (not working group, $\mathrm{n}=289$ ), or normally employed but chose not to work (ENK group, $\mathrm{n}=399$ ), on the day monitoring was performed. Thus, the data presented in this study refer to these 
Table 1 Work status and patient characteristics

\begin{tabular}{llll}
\hline & Not working $(\mathrm{n}=289)$ & Working $(\mathrm{n}=245)$ & ENK $(\mathrm{n}=399)$ \\
\hline Demography & & & \\
Age (y) & $22.3(4.9)$ & $27.0(4.1)^{*}$ & $25.5(4.9)^{*}$ \\
Gestation (weeks) & $20.7(1.3)$ & $20.3(1.6)$ & $20.2(1.5)$ \\
Smoker & $144(50 \%)$ & $71(29 \%)^{*}$ & $135(34 \%)^{*}$ \\
Drinker & $98(34 \%)$ & $92(37 \%)$ & $126(32 \%)$ \\
Marital status & $54(19 \%)$ & $162(67 \%)^{*}$ & $207(52 \%)^{*}$ \\
Body mass index (kg/m $\left.{ }^{2}\right)$ & $24.5(3.5)$ & $24.6(2.9)$ & $25.0(3.5)$ \\
& & & \\
Delivery & $39.3(2.2)$ & $39.5(1.8)$ & $39.3(2.5)$ \\
Delivery gestation (weeks) & $3347(577)$ & $3395(552)$ & $3431(608)$ \\
Birth weight (g) & $37(12.8 \%)$ & $46(18.8 \%)$ & $55(13.8 \%)$ \\
Caesarean section & $22(7.7 \%)$ & $37(15.2 \%)$ & $40(10.2 \%)$ \\
Induction of labour & $3(1.0 \%)$ & $10(4.0 \%)^{*}$ & $9(2.2 \%)$ \\
Pre-eclampsia & $11(3.8 \%)$ & $15(6.1 \%)$ & $32(8.0 \%)^{*}$ \\
Gestational hypertension & & & \\
\hline
\end{tabular}

${ }^{*} \mathrm{P}<0.01$ versus the not working group. Data, are mean (SD) or number (\%). Missing data:smoking, alcohol, marital status 8 cases; body mass index 21 cases.

933 women. The ENK group were self selected in that at recruitment, during their booking visit ( 12 weeks gestation) women were informed that the monitors were designed to be worn during a normal working day. The main focus of our study is the comparison between the working and not working groups. The women were followed up throughout pregnancy for the development of hypertensive complications (pre-eclampsia and gestational hypertension) defined in accordance with International Society for the Study of Hypertension in Pregnancy. ${ }^{12}$ Hypertension is defined as one diastolic blood pressure reading of greater than or equal to $110 \mathrm{~mm}$ $\mathrm{Hg}$ or two consecutive diastolic blood pressure readings of greater than or equal to $90 \mathrm{~mm} \mathrm{Hg}$ at least four hours apart. Significant proteinuria is defined as greater than or equal to $300 \mathrm{mg}$ total protein in a 24 hour urine collection, or if this is not available $1+$ proteinuria by dipstick on two consecutive occasions at least four hours apart. Gestational proteinuric hypertension (pre-eclampsia) is defined as hypertension in combination with proteinuria developing after 20 weeks' gestation in a previously normotensive, non-proteinuric woman.

Data were analysed using DataDesk Version 6 (Data Description Inc, Ithaca, NY) and Stata Release 5 (Stata Corporation, College Station, Texas, USA). Adjusted means and confidence intervals were calculated using a regression based approach described by Garrett in which covariates (including binary variables) are set to their mean levels. ${ }^{13}$ Factors included in this analysis included age, body mass index, gestation at monitoring, smoking, alcohol intake, marital status, and work status. Multinomial (polytomous) logistic regression was used to estimate the relation between working and the occurrence of either gestational hypertension or preeclampsia, and to adjust this estimate for possible confounders including age, smoking, body mass index, and marital status. These relations are expressed as odds ratios compared with the unemployed group.

Work was classified using the job title into three job categories ("Standing", "Active" or "Sedentary") as previously described..$^{14}$ One way analysis of variance followed by Scheffe post hoc tests were used to analysis the effect of job category on blood pressure levels in the at work group.

\section{RESULTS}

\section{Demography}

Table 1 shows the clinical characteristics at the time of ambulatory blood pressure monitoring. Women who were not working were significantly younger than women who worked. They also had significantly higher smoking prevalence and were more likely to be unmarried (all $\mathrm{p}<0.01$ ). There was no significant difference in gestation at monitoring or maternal body mass index between the three groups.

Table 2 Ambulatory blood pressure levels

\begin{tabular}{|c|c|c|c|c|c|c|}
\hline & \multicolumn{2}{|c|}{ Not working ( $n=289$ ) } & \multicolumn{2}{|l|}{ Working ( $n=245$ ) } & \multicolumn{2}{|l|}{ ENK $(n=399)$} \\
\hline & Unadjusted & Adjusted & Unadjusted & Adjusted & Unadjusted & Adjusted \\
\hline \multicolumn{7}{|l|}{ Daytime } \\
\hline Systolic & $\begin{array}{l}115.7 \\
(114.9 \text { to } 116.5)\end{array}$ & $\begin{array}{l}115.0 \\
(114.2 \text { to } 115.9)\end{array}$ & $\begin{array}{l}116.5 \\
(115.6 \text { to } 117.3)\end{array}$ & $\begin{array}{l}117.1^{* *} \\
(116.2 \text { to } 118.0)\end{array}$ & $\begin{array}{l}115.5 \\
(114.8 \text { to } 116.2)\end{array}$ & $\begin{array}{l}115.6 \\
(114.9 \text { to } 116.3)\end{array}$ \\
\hline Diastolic & $\begin{array}{l}69.3 \\
(68.7 \text { to } 69.9)\end{array}$ & $\begin{array}{l}69.4 \\
(68.7 \text { to } 70.1)\end{array}$ & $\begin{array}{l}70.8^{*} \\
(70.1 \text { to } 71.5)\end{array}$ & $\begin{array}{l}70.8^{* *} \\
(70.1 \text { to } 71.6)\end{array}$ & $\begin{array}{l}69.2^{* *} \\
(68.6 \text { to } 69.7)\end{array}$ & $\begin{array}{l}69.1 \\
(68.6 \text { to } 69.7)\end{array}$ \\
\hline \multicolumn{7}{|l|}{ Night-ime } \\
\hline Systolic & $\begin{array}{l}99.7 \\
(98.9 \text { to } 100.5)\end{array}$ & $\begin{array}{l}99.1 \\
(98.3 \text { to } 100.0)\end{array}$ & $\begin{array}{l}98.2^{* *} \\
(97.4 \text { to } 99.0)\end{array}$ & $\begin{array}{l}98.9 \\
(98.0 \text { to } 99.7)\end{array}$ & $\begin{array}{l}99.0 \\
(98.3 \text { to } 99.6)\end{array}$ & $\begin{array}{l}99.0 \\
(98.3 \text { to } 99.6)\end{array}$ \\
\hline Diastolic & $\begin{array}{l}53.8 \\
(53.2 \text { to } 54.4)\end{array}$ & $\begin{array}{l}54.0 \\
(53.4 \text { to } 54.6)\end{array}$ & $\begin{array}{l}53.6 \\
(53.0 \text { to } 54.2)\end{array}$ & $\begin{array}{l}53.5 \\
(52.8 \text { to } 54.1)\end{array}$ & $\begin{array}{l}53.8 \\
(53.3 \text { to } 54.2)\end{array}$ & $\begin{array}{l}53.7 \\
(53.2 \text { to } 54.2 \text { ) }\end{array}$ \\
\hline \multicolumn{7}{|l|}{24 hour } \\
\hline Systolic & $\begin{array}{l}109.5 \\
(108.8 \text { to } 110.2)\end{array}$ & $\begin{array}{l}108.9 \\
(108.1 \text { to } 109.6)\end{array}$ & $\begin{array}{l}109.5 \\
(108.7 \text { to } 110.2)\end{array}$ & $\begin{array}{l}110.1^{*} \\
(109.3 \text { to } 110.9)\end{array}$ & $\begin{array}{l}109.0 \\
(108.4 \text { to } 109.6)\end{array}$ & $\begin{array}{l}109.1 \\
(108.5 \text { to } 109.7)\end{array}$ \\
\hline Diastolic & $\begin{array}{l}63.3 \\
(62.8 \text { to } 63.8)\end{array}$ & $\begin{array}{l}63.4 \\
(62.9 \text { to } 64.0)\end{array}$ & $\begin{array}{l}64.0 \\
(63.4 \text { to } 64.6)\end{array}$ & $\begin{array}{l}64.0 \\
(63.4 \text { to } 64.6)\end{array}$ & $\begin{array}{l}63.1^{*} \\
(62.7 \text { to } 63.5)\end{array}$ & $\begin{array}{l}63.1 \\
(62.6 \text { to } 63.5)\end{array}$ \\
\hline
\end{tabular}

${ }^{*} \mathrm{p}<0.05,{ }^{*} \mathrm{p}<0.01$ compared with the not working group. Results expressed in $\mathrm{mm} \mathrm{Hg}$ as mean $(95 \% \mathrm{Cl})$. Adjusted means calculated to allow for age, body mass index, smoking, drinking, and marital status. 
Table 3 Odds ratios of hypertensive outcomes

\begin{tabular}{lllll}
\hline & Pre-eclampsia & $\mathrm{p}$ & Gestational hypertension & $\mathrm{p}$ \\
\hline $\begin{array}{lllll}\text { Unadjusted } \\
\quad \text { Working }\end{array}$ & $4.13(1.12$ to 15.19$)$ & 0.03 & $1.69(0.76$ to 3.75$)$ & 0.20 \\
$\quad$ ENK & $2.29(0.62$ to 8.65$)$ & 0.22 & $2.20(1.10$ to 4.50$)$ & 0.02 \\
$\begin{array}{l}\text { Adjusted* } \\
\text { Working }\end{array}$ & $5.48(1.08$ to 27.76$)$ & 0.04 & $1.25(0.52$ to 3.00$)$ & 0.62 \\
$\quad$ ENK & $2.70(0.54$ to 13.45$)$ & 0.22 & $1.57(0.73$ to 3.36$)$ & 0.73 \\
$\begin{array}{l}\text { Adjusted for BPt } \\
\quad \text { Working }\end{array}$ & $4.73(0.90$ to 24.82$)$ & 0.07 & $1.04(0.43$ to 2.56$)$ & 0.92 \\
ENK & $2.83(0.55$ to 14.61$)$ & 0.21 & $1.55(0.71$ to 3.39$)$ & 0.28 \\
\hline
\end{tabular}

Results are expressed as odds ratio ( $95 \%$ confidence intervals) for developing pre-eclampsia compared with the not working group. *Adjusted for age, smoking, body mass index, and marital status; †mean daytime systolic and diastolic blood pressure included as additional confounders.

\begin{tabular}{|c|c|c|c|}
\hline & Sedentary $(n=135)$ & Standing $(n=50)$ & Active $(n=49)$ \\
\hline \multicolumn{4}{|l|}{ Daytime } \\
\hline Systolic & 116.1 (115.0 to 117.2 ) & 116.0 (114.1 to 117.9 ) & 118.2 (116.2 to 120.2 ) \\
\hline Diastolic & 70.1 (69.2 to 71.0 ) & 71.5 (70.0 to 73.0$)$ & 72.4 (70.5 to 74.3$)$ \\
\hline \multicolumn{4}{|l|}{ Night-time } \\
\hline Systolic & 97.9 (96.8 to 99.0 ) & 97.4 (95.7 to 99.1$)$ & 99.6 (97.5.3 to 101.7$)$ \\
\hline Diastolic & 53.0 (52.2 to 53.8$)$ & 53.5 (52.4 to 54.6$)$ & $55.2^{*}(53.6$ to 56.8$)$ \\
\hline \multicolumn{4}{|l|}{24 hour } \\
\hline Systolic & 109.1 (108.2 to 110.0 ) & 108.9 (107.3 to 110.5$)$ & 111.2 (109.3 to 113.1$)$ \\
\hline Diastolic & $63.4(62.6$ to 64.2$)$ & $64.4(63.3$ to 65.5$)$ & $65.6 *(64.0$ to 67.2$)$ \\
\hline
\end{tabular}

\section{Ambulatory blood pressure levels}

Daytime diastolic blood pressure was significantly higher in the working group $(\mathrm{p}<0.05)$ compared with the not working group. In addition, night time systolic in the working group $(\mathrm{p}<0.01)$ and daytime diastolic in the ENK group $(\mathrm{p}<0.01)$ were significantly lower than the not working group (table 2 ). However, when adjusted for age, body mass index, smoking, drinking, and marital status, the persistent significant differences were that women at work had higher mean daytime systolic $(\mathrm{p}<0.01)$ and diastolic $(\mathrm{p}<0.01)$ and 24 hour systolic pressures $(p=0.03)$ compared with those not working (table 2). In addition, this approach also identified that maternal age was a inversely related to daytime systolic $(\mathrm{p}<0.001)$, night time systolic $(\mathrm{p}<0.001)$ and 24 hour systolic $(\mathrm{p}<0.001)$ blood pressure. This inverse relation was still present when stratified analysis by work group was performed (data not shown). Body mass index was a significant positive predictor of daytime systolic $(\mathrm{p}<0.001)$ and diastolic $(\mathrm{p}<0.001)$ and 24 hour systolic $(\mathrm{p}<0.001)$ blood pressure. Smoking was a significant positive predictor of daytime $(p=0.001)$ and 24 hour systolic $(p=0.015)$ blood pressure. Importantly, there were no significant differences in blood pressure levels between the not working group and the ENK group.

\section{Pregnancy outcomes}

There were no significant differences between the three work status groups with regards to gestation at delivery, birth weight or rate of caesarean section or induction. The rate of subsequent development of pre-eclampsia was higher (odds ratio $4.1,95 \%$ CI 1.1 to $15.2, \mathrm{p}=0.03$ ) in those women at work compared with those not working. In addition, the rate of subsequent development of gestational hypertension was significantly higher (odds ratio $2.2,95 \% \mathrm{CI} 1.1$ to $4.5, \mathrm{p}=0.02$ ) in the ENK group compared with those not working (table 1). The association between pre-eclampsia and maternal work remained significant (odds ratio 5.5, 95\% CI 1.1 to 27.8, $\mathrm{p}=0.04$ ) even after allowing for the confounding factors of age, smoking, body mass index, and marital status. When daytime systolic and diastolic blood pressure were added to the regression analysis the odds ratio for pre-eclampsia remained high but did not quite reach statistical significance (odds ratio $4.7,0.90$ to $24.8, p=0.066$ ). In contrast, after allowance for confounders the odds ratios for gestational hypertension were close to unity (table 3 ). Birth weight and placental weight were not predicted by work status or blood pressure levels.

\section{Job category}

The proportions of women in the working group who were in jobs classified as sedentary, standing or active were $21 \%, 21 \%$, $58 \%$ respectively was significantly different from those in the ENK group- $22 \%, 44 \%, 34 \%\left(\chi^{2}=15.2, p<0.001\right)$. Within the working group women who had jobs classified as active had significantly higher mean daytime diastolic $(p=0.065)$, night time diastolic $(\mathrm{p}=0.04)$ and 24 hour diastolic $(\mathrm{p}=0.02)$ blood pressure compared with women in jobs classified as sedentary (table 4). There was no relation between job category and hypertensive outcome during pregnancy $\left(\chi^{2}=0.58, \mathrm{p}=0.96\right)$.

\section{DISCUSSION}

We have shown a significant independent relation between maternal work and ambulatory blood pressure levels in mid-pregnancy. In addition, we found that maternal work was significantly associated with the subsequent development of pre-eclampsia. After adjustment for possible confounders, women in the working group, were still almost five times more likely to develop pre-eclampsia than those not working. In contrast, there were no significant blood pressure differences between women in the ENK group and those not working.

The cohort we have studied was drawn from the antenatal clinics of the Rotunda Hospital Dublin. The proportion of women who developed pre-eclampsia was $2.2 \%$ and is similar to that reported elsewhere in a healthy primigravid population. ${ }^{15}$ The homogeneous nature of this cohort (all white, all primigravid), the exclusion of women with 


\section{Key points}

- A greater proportion of women work outside the home dur ing pregnancy.

- The impact of maternal work on pregnancy outcome is still poorly defined.

- We demonstrate that maternal work is associated with higher levels of ambulatory pressure and with the subsequent development of pre-eclampsia.

important blood pressure confounders (pre-existing hypertension, renal disease, and diabetes mellitus) and the size of the study decrease the chance that the associations described are attributable to bias. However, an important limitation of our data is that the work status of the women was defined at the time of monitoring (18-24 weeks). This may not reflect their work status throughout pregnancy. In addition, the ENK group were self selected in that, despite being informed that the monitors were designed to be worn on a work day, they chose to absent themselves from work. The different pattern of job categories compared with the working group and the fact that their ambulatory blood pressure readings reflected a nonworking day means that the data from the ENK group are more difficult to interpret. We have therefore focused on the comparison between the working and not working groups but included the ENK group results for completeness.

We have confirmed the previously reported positive relation of both body mass index and smoking with blood pressure levels. ${ }^{16}{ }^{17}$ We did not, however, confirm the results of many studies that have observed that non-smokers are at higher risk of developing pre-eclampsia. ${ }^{18-20}$ In addition, we observed a strong inverse relation between age and systolic blood pressure. To our knowledge, this is the first time that this relation has been noted. In contrast, several studies in nonpregnant populations have reported that ambulatory blood pressure increases with age. ${ }^{21}$ We can only speculate that this finding may be specific to pregnancy but the underlying mechanism is not apparent.

Our findings are in keeping with other reports that maternal work in pregnancy is associated with an increased risk of pre-eclampsia. ${ }^{252}$ It has been suggested that the association is strongest in those women who are employed in high stress jobs, defined in the widely used occupational database developed by Karasek, as jobs with a high psychological demand and low decision latitude. ${ }^{22}{ }^{23}$ Our study design did not allow us to define which features of work predispose to preeclampsia. Nor could we allow for important socioeconomic factors that may have confounded our results. While job categorisation by title did show some significant effects on absolute blood pressure levels much more detailed information about the precise physical activity levels and the perceived stress levels would be required to isolate factors within work likely to predispose to the development of pre-eclampsia. This may also explain why we did not find an association between birth or placental weight and work. It is now widely accepted that it is specifically heavy strenuous physical work, especially if there is prolonged standing, that is associated with low birth weight. ${ }^{24} 25$ The explanation for the association between work and pre-eclampsia is unknown, but it has been suggested that the stress of work leads to an increased release of catecholamines and a daylong sympathetic response that increases blood pressure. ${ }^{26}$ Sympathetic overactivity has recently been reported in pre-eclampsia. ${ }^{27}$ It is, therefore, an important observation of our study that this association was independent of mid-pregnancy blood pressure (table 3). The different pattern of results noted for gestational hypertension (hypertension alone) compared with preeclampsia (proteinuric hypertension) further emphasises the need to clearly distinguish these two outcomes. In contrast with pre-eclampsia, gestational hypertension is associated with little or no excess morbidity during pregnancy. However, on long term follow up, it is clear that gestational hypertension a marker for the development of essential hypertension. ${ }^{28}$ This is in keeping with our observation, that after allowance for confounders, the relative risk ratios for gestational hypertension were close to unity suggesting that any effect of work on the development of gestational hypertension may be blood pressure mediated.

The demonstration of an increase in absolute blood pressure levels in association with maternal work mirrors the findings of studies on the effect of work on blood pressure levels in non-pregnant populations. The absence of any blood pressure difference between women in the ENK group compared with those in the not working group suggests that the relation may be both causal and reversible. While, the differences in absolute blood pressure levels between the groups were small it is important to note that our measurements were taken at 18-24 weeks when blood pressure levels are at their nadir. In keeping with the study of Churchill et al, we did not find a relation between ambulatory blood pressure levels in midpregnancy and birth weight. ${ }^{6}$ In contrast, Churchill et al did report that there is a continuous inverse relation between fetal growth and maternal ambulatory blood in the latter part of pregnancy. ${ }^{6}$ Thus, even within the normal blood pressure range differences between work and non-work blood pressures in late pregnancy may impact on pregnancy outcome.

We believe that the association we have demonstrated between maternal work and increased blood pressure levels may have clinical implications for the management of blood pressure in late pregnancy. In the third trimester, the physical burden of pregnancy is more marked, vascular reactivity is higher $^{29}$ and blood pressure levels are closer to threshold values requiring increased surveillance or intervention. For clinical management, it would be important to be able to compare blood pressure on a work day with a non-work day in an individual woman. Ambulatory blood pressure measurement makes an assessment of these differences a practical clinical option.

Our study provides information about one aspect of work in pregnancy. Further studies using ambulatory blood pressure are now warranted. They should focus on the third trimester and attempt to define the characteristics of work that alter blood pressure and the characteristics of work that predispose to pre-eclampsia. They should include multiparous women to allow for the effect of work at home. Ultimately these data may be important to allow the clinician to optimise the management of hypertension in pregnancy.

\section{ACKNOWLEDGEMENTS}

We acknowledge with gratitude the contribution of research midwives Audrey McMahon and Anna O'Sullivan.

Funding: this study was made possible by grants from the Friends of the Rotunda and the Wellcome Trust.

Conflicts of interest: none.

\section{Authors' affiliations}

J R Higgins, J J Walshe, M R N Darling, Rotunda Hospital, Dublin, Ireland

J R Higgins, Department of Obstetrics and Gynaecology, University College Cork, Ireland

R M Conroy, Department of Epidemiology and Preventative Medicine, Royal College of Surgeons in Ireland, Dublin, Ireland

\section{REFERENCES}

1 Marcus D. Employment characteristics of mothers during pregnancy. In: National Center for Health Statistics, PHS, DHSS. Health, united States, 1983. Hyattville. MD:US Government Printing Office, 25-31.

2 Klebanoff MA, Shiono PH, Rhoads GG. Outcomes of pregnancy in a national sample of resident physicians. N Engl J Med 1990;323:10405 . 
3 Homer CJ, James SA, Siegel E. Work-related psychosocial stress and risk of preterm, low birthweight delivery. Am J Public Health 1990;80:173-7.

4 Launder LJ, Villar J, Kestler E, et al. The effect of maternal work on fetal growth and duration of pregnancy: a prospective study. Br J Obstet Gynaecol 1990;97:62-70.

5 Eskenazi B, Fenster L, Sidney S. A multivariate analysis of risk factors for preeclampsia. JAMA 1991;266:237-41

6 Churchill D, Perry IJ, Beevers DG. Ambulatory blood pressure in pregnancy and fetal growth. Lancet 1997:349:7-10.

7 Coats AJS. Reproducibility or variability of casual and ambulatory blood pressure data: implications for clinical trials. J Hypertens 1990; 8 (suppl 6): S17-20.

8 Baba S, Ozawa H, Nakamoto Y, et al. Enhanced blood pressure response to regular daily stress in urban hypertensive men. J Hypertens 1990;8:647-55.

9 Pieper C, Warren K, Pickering TG. A comparison of ambulatory blood pressure and heart rate at home and work on work and non-work days. $J$ Hypertens 1993;11:177-83.

10 Higgins JR, Walshe JJ, Halligan A, et al. Can 24-hour ambulatory blood pressure measurement predict the development of hypertension in primigravidae? Br J Obstet Gynaecol 1997; 104:356-62.

11 Shennan AH, Kissane J, de Swiet M. Validation of the Spacelabs 90207 ambulatory blood pressure monitor for use in pregnancy. $\mathrm{Br} \mathrm{J}$ Obstet Gynaecol 1993;100:904-8.

12 Davey DA, MacGillivray I. The classification and definition of the hypertensive disorders of pregnancy. Am J Obstet Gynecol 1988; 158:892-8.

13 Garrett JM. Enhancements for calculation of adjusted means and proportions. Stata Technical Bulletin 1998;43:16-24.

14 Teitelman AM, Welch LS, Hellenbrand KG, et al. Effect of maternal work activity on preterm birth and low birthweight. Am J Epidemiol 1990;131:104-13.

15 Cooper DW, Brennecke SP, Wilton AN. Genetics of pre-eclampsia. Hypertension in Pregnancy 1993;12:409-12

16 Harshfield GA, Alpert BS, Willey ES et al. Race and gender influence ambulatory blood pressure patterns of adolescents. Hypertension $1989 ; 14: 598-603$
17 Narkiewicz K, Maraglino G, Biasion T, et al. Interactive effect of cigarettes and coffee on daytime systolic blood pressure in patients with mild essential hypertension. HARVEST Study Group (Italy). Hypertension Ambulatory Recording Venetia Study. J Hypertens 1995;13:965-70.

18 Sibai BM, Gordon T, Thom E, et al. Risk factors for pre-eclampsia in healthy nulliparous women: a prospective multicenter study. The National Institue of Health and Human Development Network of Maternal-Fetal Medicine Units. Am J Obstet Gynecol 1995;172:642-8.

19 Spinillo A, Capuzzo E, Egbe TO, et al. Cigarette smoking in pregnancy and risk of pre-eclampsia. J Hum Hypertens 1994;8:771-5.

20 Cnattingius S, Mills JL, Yuen J, et al. The paradoxical effect of smoking in pre-eclamptic pregnancies: smoking reduces the incidence but increases the rates of perinatal mortality, abruptio placentae, and intrauterine growth restriction. Am J Obstet Gynecol 1997; 177:156-61.

21 Staessen J, Fagard R, Lijnen P et al. The mean and range of ambulatory blood pressure in normotensive subjects from a meta-analysis of 23 studies. Am J Cardiol 1991;67:723-7.

22 Klonoff-Cohen HS, Cross JL, Pieper CF. Job stress and preeclampsia. Epidemiology 1996;7:245-9.

23 Karasek RA. Job demands, job decision latitude, and mental strain: implications for job redesign. Admin Sci Q 1979;24:285-308

24 Spinillo A, Capuzzo E, Baltaro F, et al. The effect of work activity in pregnancy on the risk of fetal growth retardation. Acta Obstet Gynecol Scand 1996;75:531-6.

25 Henriksen TB, Hedegaard M, Secher NJ. Standing and walking at work and birthweight. Acta Obstet Gynecol Scand 1995;74:509-16.

26 James GD, Schlussel YR, Pickering TG. The association between daily blood pressure and catecholamine variability in normotensive working women. Psychosom Med 1993;55:55-60.

27 Schobel HP, Fischer T, Heuszer K, et al. Preeclampsia-a state of sympathetic overactivity. N Engl J Med 1996;14:1480-5

28 National high blood pressure education program working group report on high blood pressure in pregnancy. Am J Obstet Gynecol 1990;163:1689-712.

29 Gant NF, Daley GL, Chand S, et al. A study of angiotensin II pressor response throughout primigravid pregnancy. J Clin Invest 1973;52:2682-9. 